\title{
Colorimetry-Based Detection of Biomarkers in Exhaled Breath for Predicting COVID-19 Disease
}

Fatimatulzahraa Alsaedi ${ }^{1}$, Najam-US-Sahar Riyaz ${ }^{1}$, Hagar Morsy², Raghad Abuznad ${ }^{1}$, Alaa Elsafi Ahmed $^{1}$, Aeshah Alruwaili², Muna Ibrahim ${ }^{1}$,Mizaj Shabil Sha ${ }^{3}$, Haseena Onthath ${ }^{3}$, Muni Raj

Maurya ${ }^{3}$, Kishor Kumar Sadasivuni ${ }^{3 .}{ }^{*}$ and Peter Kasak ${ }^{3}$

${ }^{1}$ College of Art and Science-Chemistry and Earth Science, Qatar University, Qatar

2Department of Chemistry, Qatar University, Qatar

${ }^{3}$ Center for Advanced Materials, Qatar University, Qatar

*kishorkumars@yahoo.com

Undergraduate Student, Health and Biomedical Science

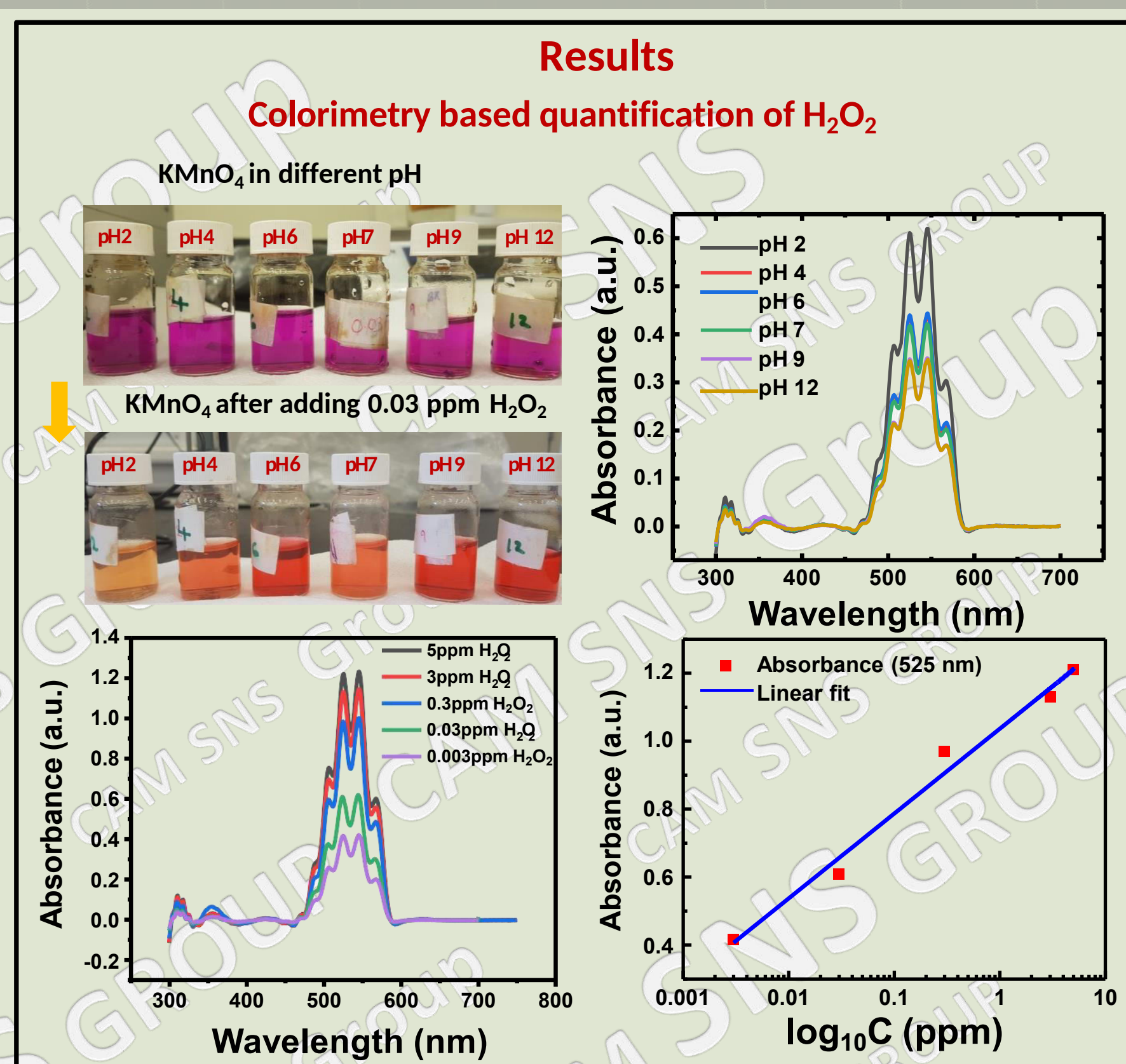

- Color change, effect of pH, effect of $\mathrm{H}_{2} \mathrm{O}_{2}$ concentration of and calibration curve for Limit of detection calculation.

- Estimated $\mathrm{H}_{2} \mathrm{O}_{2}$ LOD was 0.01 ppm.

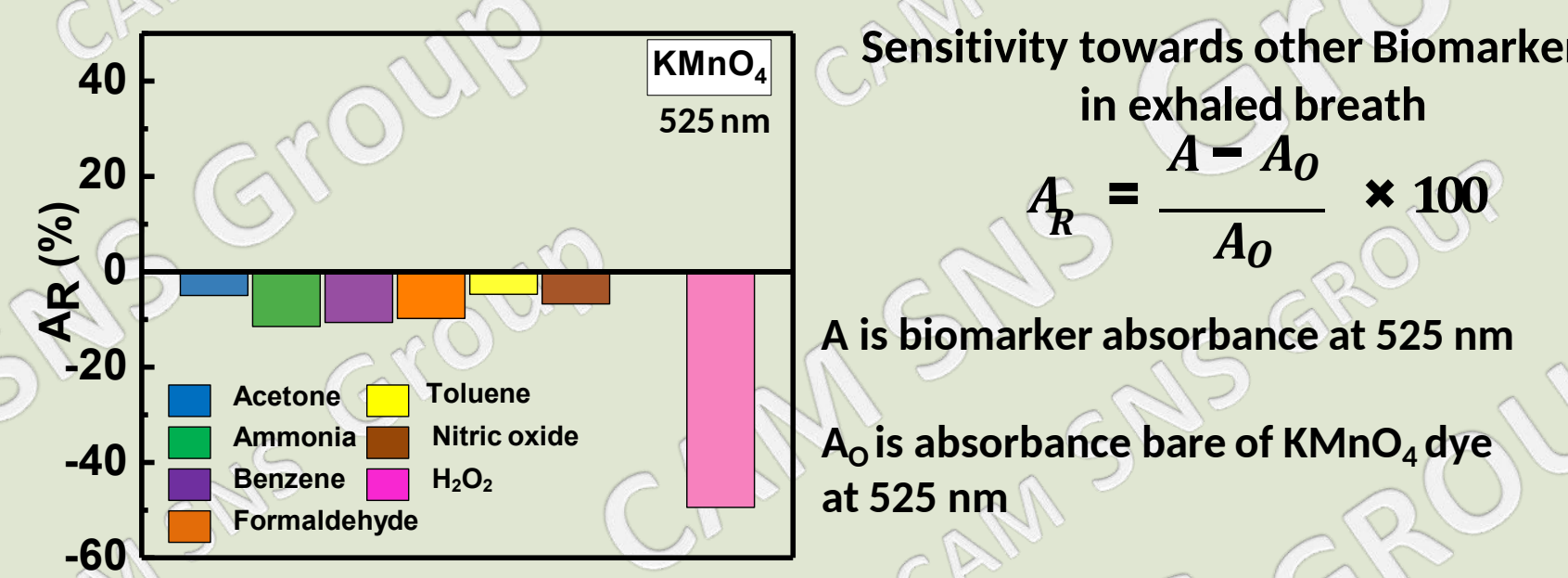

Colorimetry based quantification of nitric oxide (NO)
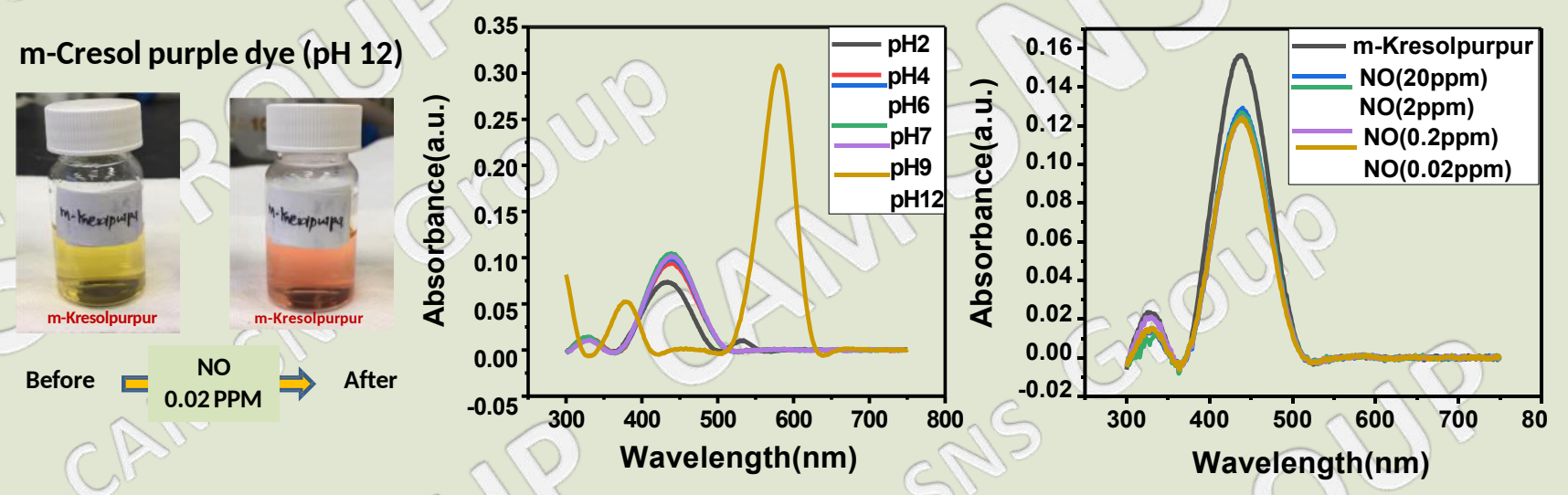

Key Features

\begin{tabular}{|l|lll|}
\hline Point-of-care & Portable & Low cost \\
\hline Naked-eye detection & Increase number of testing & Regular monitoring \\
\hline
\end{tabular}

\section{Conclusion}

$>$ The dyes show increase in the absorption peak with increase in the ppm level of $\mathrm{H}_{2} \mathrm{O}_{2}$ and $\mathrm{NO}$

The dyes offers detection limit of $0.01 \mathrm{ppm}$ towards $\mathrm{H}_{2} \mathrm{O}_{2}$ and $0.02 \mathrm{ppm}$ towards NO.

$>$ The dyes shows nearly linear increase in the absorption peak with increase in the ppm level of $\mathrm{H}_{2} \mathrm{O}_{2}$.

- The linear increase behaviors of the dyes assists in easy characterization of various ppm level of $\mathrm{NO}$ and $\mathrm{H}_{2} \mathrm{O}_{2}$.

This work was carried by the UREP grant \# UREP27-044-3-016 from the Qatar National Research Fund (a member of Qatar Foundation). The statements made herein are solely the responsibility of the authors" 